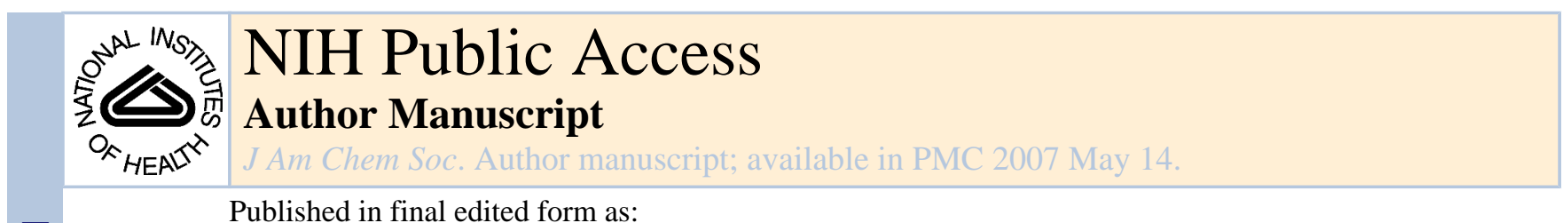

Published in final edited form as:

J Am Chem Soc. 2006 July 26; 128(29): 9302-9303.

\title{
Symbiotic Reagent Activation: Oppenauer Oxidation of Magnesium Alkoxides by Silylglyoxylates Triggers Second-Stage Aldolization
}

\author{
Xin Linghu, Andrew D. Satterfield, and Jeffrey S. Johnson * \\ Department of Chemistry, University of North Carolina at Chapel Hill, Chapel Hill, North Carolina \\ 27599-3290
}

The aldol reaction is the preeminent method for the introduction of the $\beta$-hydroxy carbonyl function, and its development has been marked by significant advances in utility to synthetic practitioners. ${ }^{1}$ The most recent chapter in this evolution is the introduction of catalysts and reagents that enable direct and selective formation of the nucleophilic enol component in the presence of the carbonyl electrophile. ${ }^{2}$ Although electrophile synthesis is not typically factored into the overall efficiency of a given aldol addition, it is instructive to consider that when the reaction is applied in complex fragment couplings, the aldolization step is often preceded by an obligatory oxidation event that provides the requisite aldehyde or ketone coupling partner. 3 A compelling argument may be advanced, therefore, that the most efficient direct aldol reaction would be one in which both the enolate nucleophile and carbonyl electrophile are simultaneously generated in situ. This communication provides the conceptual framework for such a process in the form of a symbiotic redox reaction between an alcohol and a silylglyoxylate that mutually activates both reaction components for aldolization in the second stage (eq 1).

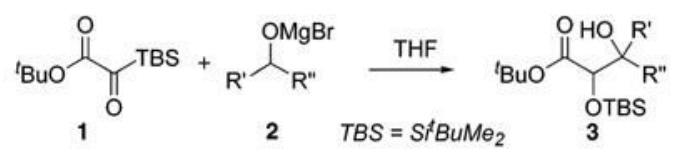

Silylglyoxylates ${ }^{4} \mathbf{1}$ and $\mathbf{5}$ were recently described as useful conjunctive agents for coupling alkynylzinc halides and aldehydes. ${ }^{5}$ The genesis of the current study was the observation of hydroxy-silane $\mathbf{6}$ and ynone $\mathbf{7}$ as minor byproducts in a reaction between zinc alkoxide $\mathbf{4}$ and silyl glyoxylate 5 (eq 2) that was designed to probe the mechanism of the aforementioned threecomponent coupling. We hypothesized that these byproducts resulted from an Oppenauer oxidation/Meerwein-Ponndorf-Verley (MPV) reduction ${ }^{6-8}$ between 4 and $\mathbf{5}$. In contrast to other nucleophiles that react with $\mathbf{5}$, the hydride transfer did not trigger [1,2]-Brook rearrangement. 9

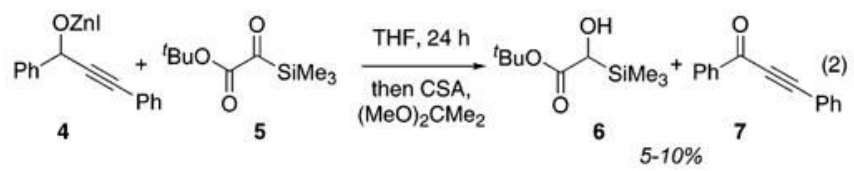

E-mail: jsj@unc.edu.

Supporting Information Available: Experimental procedures and compound characterization data. This material is available free of charge via the Internet at http://pubs.acs.org. 
If reaction conditions could be suitably modified such that the Oppenauer/MPV process did cause $\mathrm{C} \rightarrow \mathrm{O}$ silyl migration $(\mathbf{8} \rightarrow \mathbf{9}),{ }^{10}$ the resulting products from the redox reaction would be a glycolate enolate and ketone or aldehyde poised to undergo aldolization (Scheme 1). It was projected that the identity of the metal cation would be crucial in governing the efficiency of each proposed step; therefore, an evaluation of suitable candidates was initiated.

As commonly employed catalysts for MPV/Oppenauer reactions, aluminum alkoxides provided a logical starting point for this inquiry (Table 1). ${ }^{11}$ Surprisingly, we observed no reaction with $\mathrm{MeAlCl}_{2}$ (entry 1), while $n \mathrm{BuLi}$ and $\mathrm{Bu}_{3} \mathrm{La}$ provided only the direct addition/ rearrangement product 11 (entries 2 and 3). Selective generation of desired aldol product 3a was achieved with a magnesium alkoxide ${ }^{12,13}$ generated in THF (entry 4), and an improved yield and diastereomer ratio was realized when the reaction was conducted in 2:1 THF/ $\mathrm{CH}_{2} \mathrm{Cl}_{2}$ (entry 5). 14

With the identification of the optimal metal cation, we next evaluated other coupling partners in the reaction. Alkoxides resulting from deprotonation of alcohols with EtMgBr were initially investigated (Table 2). Results were good for a variety of alcohols with yields from 63 to $97 \%$. Notably, primary aliphatic alcohols delivered the aldol products with synthetically useful levels of anti diastereocontrol (Table 2, entries 1-4). ${ }^{15}$ Although the details of the transition structure will require further elucidation, the predominance of the anti isomer is congruent with the recent observation by Evans and co-workers of anti propionates from $(Z)$-magnesium enolates. 16 The boat-like transition structure $\mathbf{1 0}$ may thus be construed as a tentative model for the observed stereochemical outcome $\left(R^{\prime}=H\right)$.

Benzylic alcohols provided the aldol adducts with superior yields but negligible diastereocontrol (entries 5-7). Perhaps most strikingly, secondary alcohols function effectively in this reaction to deliver highly substituted ketone aldol adducts (entries 8 and 9).

The success of these latter reactions led us to evaluate a three-component coupling strategy wherein the requisite secondary alkoxide was formed via Grignard addition to aldehydes (Table 3). ${ }^{17}$ This simple one-step protocol facilitated access to more complex ketone aldol adducts with no reduction in reaction efficiency. In the case where significant steric differentiation exists between $\mathrm{R}^{\prime}$ and $\mathrm{R}^{\prime \prime}$, promising levels of diastereocontrol may be achieved (entry 3 ).

Epoxides may also serve as the alkoxide progenitor in conjunction with a $\mathrm{Cu}(\mathrm{I})$-catalyzed alkylation (eq 3). On the basis of the similar yield for 12a beginning from either an epoxide (eq 3) or an aldehyde (Table 3, entry 1), it appears that CuI does not interfere with the subsequent steps.

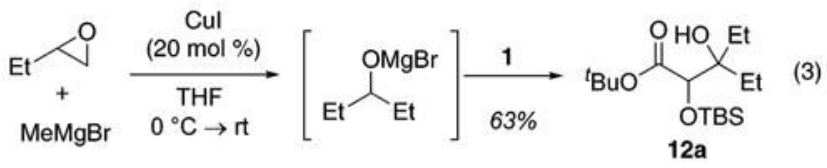

Preliminary conclusions regarding the relative rates of the individual steps of the reaction sequence may be drawn from a simple crossover experiment shown in eq 4. Exposing the magnesium alkoxide of $n$-hexanol to $\mathbf{1}$ and isobutyraldehyde resulted in an approximately equimolar mixture of aldols $\mathbf{3 a}$ and $\mathbf{3 b}$, revealing that dissociation of the aldehyde from the magnesium center is faster than Brook rearrangement and aldolization (eq 4). ${ }^{18}$ 


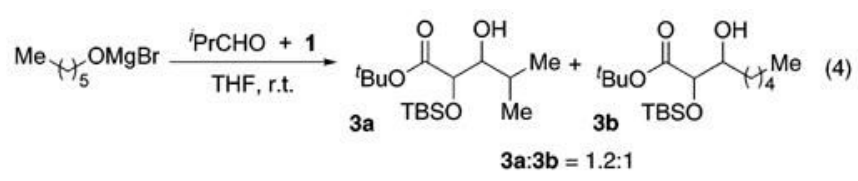

In summary, a new direct aldol reaction has been accomplished between the enolate obtained from an Oppenauer/MPV-induced [1,2]-Brook rearrangement of a silylglyoxylate and the carbonyl product of that redox reaction. The concept of symbiotic reagent activation may be applicable to other reaction classes. This possibility is the topic of ongoing investigations.

\section{Supplementary Material}

Refer to Web version on PubMed Central for supplementary material.

\section{Acknowledgements}

Funding for this work was provided by the National Institutes of Health (National Institute of General Medical Sciences, GM068443). Research support from Eli Lilly, Amgen, and GSK is gratefully acknowledged. J.S.J. is an Alfred P. Sloan Fellow and a Camille Dreyfus Teacher-Scholar.

\section{References}

1. Mahrwald, R., editor. Modern Aldol Reactions. Wiley-VCH; Weinheim, Germany: 2004.

2. For leading references, see: (a) Yoshikawa N, Yamada YMA, Das J, Sasai H, Shibasaki M. J Am Chem Soc 1999;121:4168-4178. (b) Taylor SJ, Morken JP. J Am Chem Soc 1999;121:12202-12203. (c) List B, Lerner RA, Barbas CF III. J Am Chem Soc 2000;122:2395-2396. (d) Trost BM, Ito H. J Am Chem Soc 2000;122:12003-12004. (e) Northrup AB, MacMillan DWC. J Am Chem Soc 2002;124:6798-6799. [PubMed: 12059180] (f) Jang HY, Huddleston RR, Krische MJ. J Am Chem Soc 2002;124:15156-15157. [PubMed: 12487574] (g) Evans DA, Downey CW, Hubbs JL. J Am Chem Soc 2003;125:8706-8707. [PubMed: 12862448] (h) Ooi T, Kameda M, Taniguchi M, Maruoka K. J Am Chem Soc 2004;126:9685-9694. [PubMed: 15291572]

3. For a recent example, see: Kagawa N, Ihara M, Toyota M. Org Lett 2006;8:875-878. [PubMed: 16494463]

4. Bolm C, Kasyan A, Heider P, Saladin S, Drauz K, Guenther K, Wagner C. Org Lett 2002;4:22652267. [PubMed: 12074683]

5. Nicewicz DA, Johnson JS. J Am Chem Soc 2005;127:6170-6171. [PubMed: 15853312]

6. de Graauw CF, Peters JA, van Bekkum H, Huskens J. Synthesis 1994:1007-1017.

7. Adkins H, Franklin RC. J Am Chem Soc 1941;63:2381-2383.

8. Markert M, Mahrwald R. Synthesis 2004:1429-1433.

9. For reduction of acyl silanes by organometals and metal hydrides, see: (a) Brook AG, Quigley MA, Peddle GJD, Schwartz NV, Warner CM. J Am Chem Soc 1960;82:5102-5106. (b) Reich HJ, Holtan RC, Bolm C. J Am Chem Soc 1990;112:5609-5617.

10. Brook AG. Acc Chem Res 1974;7:77-84.

11. Ooi T, Otsuka H, Miura T, Ichikawa H, Maruoka K. Org Lett 2002;4:2669-2672. [PubMed: 12153205]

12. Oppenauer, R. US Patent 2,384,335. 1945.

13. The absence of silyl migration in eq 2 and the successful use of a magnesium alkoxide to promote [1,2]-Brook rearrangement (Table 1, entry 4) contrast a recent example where $\mathrm{Mg} \rightarrow \mathrm{Zn}$ transmetalation was required to initiate silyl migration: Unger R, Cohen T, Marek I. Org Lett 2005;7:5313-5316. [PubMed: 16268566]

14. For a complete survey of conditions, see the Supporting Information.

15. (a) Notz W, List B. J Am Chem Soc 2000;122:7386-7387. (b) Andrus MB, Sekhar BBVS, Meredith EL, Dalley NK. Org Lett 2000;2:3035-3037. [PubMed: 10986101] (c) Crimmins MT, McDougall 
PJ. Org Lett 2003;5:591-594. [PubMed: 12583777] (d) Northrup AB, Mangion IK, Hettche F, MacMillan DWC. Angew Chem, Int Ed 2004;43:2152-2154.

16. Evans DA, Downey CW, Shaw JT, Tedrow JS. Org Lett 2002;4:1127-1130. [PubMed: 11922799]

17. Byrne B, Karras M. Tetrahedron Lett 1987;28:769-772.

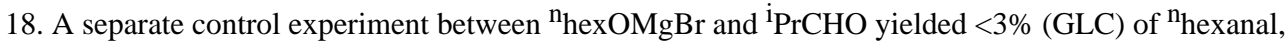
indicating that the mechanism of crossover is not MPV/Oppenauer redox between the alkoxide and the aldehyde. 


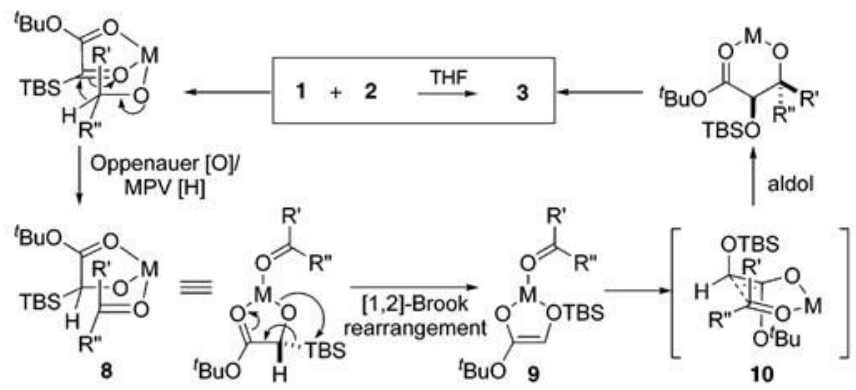

Scheme 1. 
Evaluation of Metal Alkoxides

\section{Table 1}

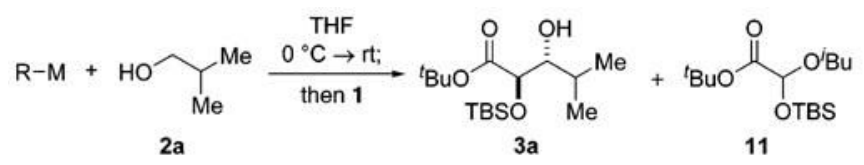

\begin{tabular}{llll}
\hline entry & $\mathbf{R}-\mathbf{M}$ & result & anti:syn $^{\boldsymbol{a}}$ \\
\hline 1 & & & n.a. \\
2 & $\mathrm{MeAlCl}_{2}$ & no reaction & n.a. \\
3 & $n-\mathrm{BuLi}$ & $40 \%$ of $\mathbf{1 1}^{b}$ & n.a. \\
4 & $\mathrm{Bu}_{3} \mathrm{La}$ & $58 \%$ of $\mathbf{1 1}^{c}$ & $6: 1$ \\
5 & $\mathrm{EtMgBr}$ & $71 \%$ of $\mathbf{3 a}^{c}$ & $10: 1$ \\
\hline
\end{tabular}

${ }^{a}$ Determined by ${ }^{1}$ H NMR spectroscopy.

$b^{b_{1}}$ NMR yield versus an internal standard.

$c_{\text {Isolated yield. }}$

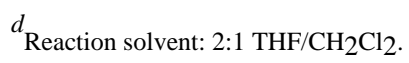


Table 2

Oppenauer Oxidation/Brook Rearrangement/Aldolization Reactions ${ }^{a}$

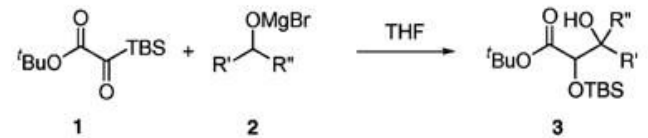

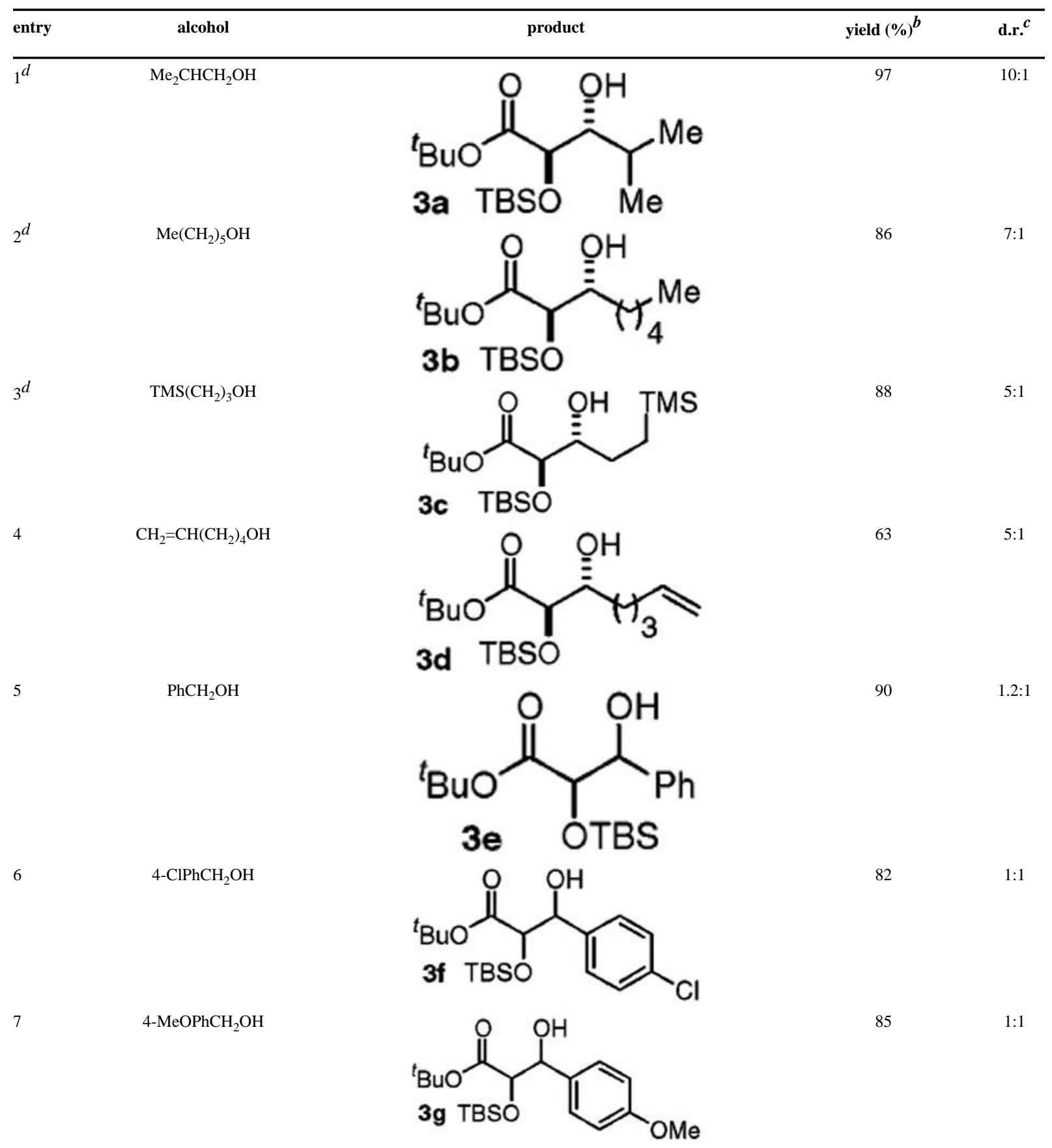




\begin{tabular}{|c|c|c|c|c|}
\hline entry & alcohol & product & yield $(\%)^{b}$ & d.r. ${ }^{c}$ \\
\hline 8 & $\mathrm{PhCH}(\mathrm{OH}) \mathrm{Me}$ & & 67 & $2.5: 1$ \\
\hline 9 & cyclohexanon & & 68 & n.a. \\
\hline
\end{tabular}

${ }^{a}$ Alcohol (1.5 equiv), $\mathrm{EtMgBr}\left(2.0\right.$ equiv), $0{ }^{\circ} \mathrm{C} \rightarrow \mathrm{rt}$; then $\mathbf{1}$ (1.0 equiv).

${ }^{b}$ Isolated yield.

${ }^{c}$ Determined by ${ }^{1} \mathrm{H}$ NMR spectroscopy; the major isomer is shown.

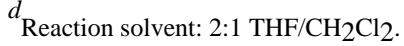




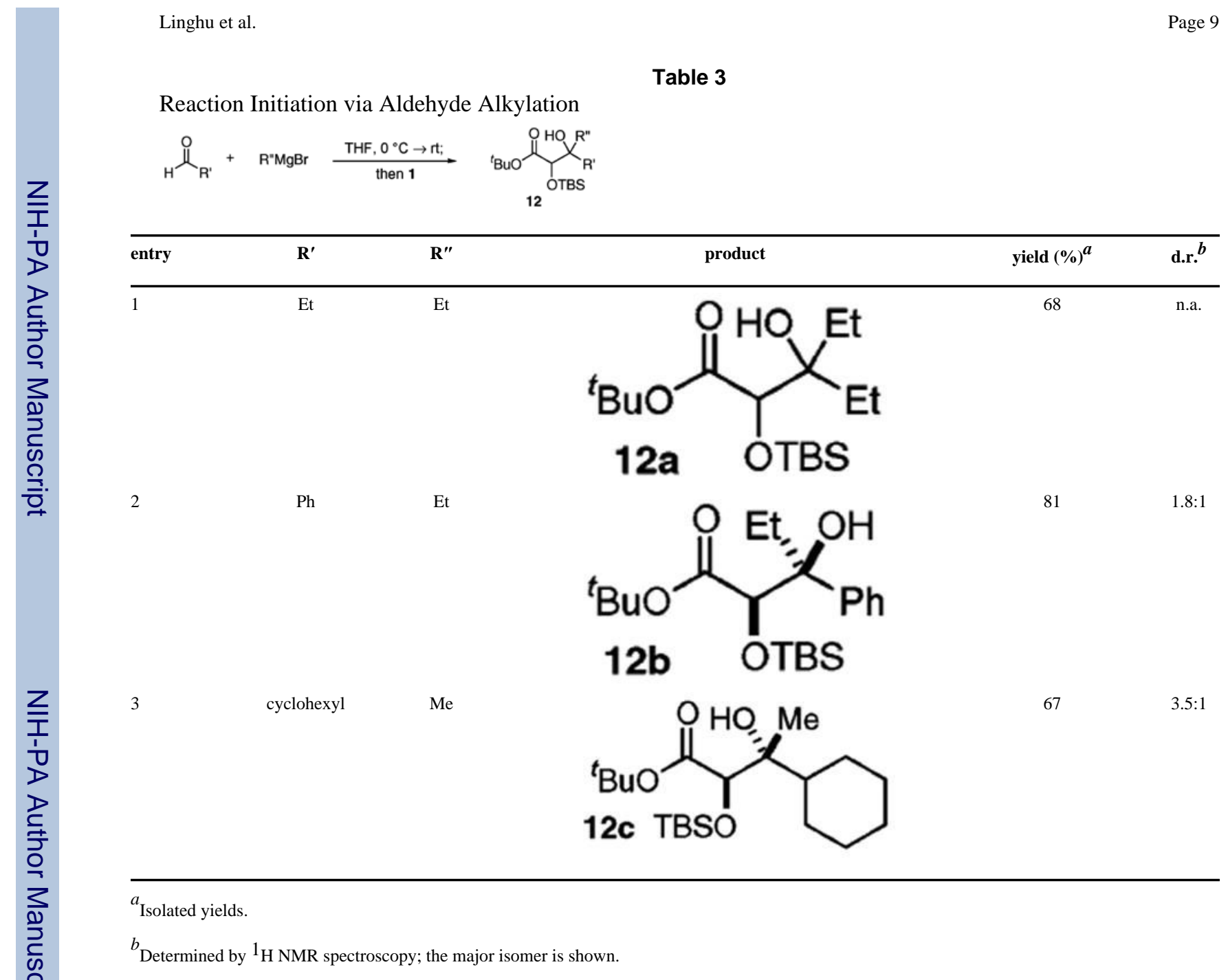

